\title{
Useful Nucleic Acid Chemistry Web Sites
}

APPENDIX 4A

Below is a listing of selected internet resources found to be of particular value by the CPNC editorial board; it is not intended to be a complete listing of all web resources cited in this manual. In addition to the sites listed here, be sure to see the Internet Resources sections at the end of selected units for specialized sites pertaining to the contents of those units.

\section{Nucleic acid structure}

Nucleic Acid Database—structural information about nucleic acids

$$
\text { http://ndbserver.rutgers.edu/NDB/ndb.html }
$$

National Center for Biotechnology (NCBI) database of 3-dimensional macromolecular structures

$$
\text { http://www.ncbi.nlm.nih.gov/Structure }
$$

Nucleic Acid Nomenclature and Structure-good overview of important structural parameters including the Dickerson movements of bases in sequence-dependent structures (tip, inclination, opening, propeller, buckle, twist, roll, slide, rise, shift, and tilt)

$$
\text { http://www.imb-jena.de/ImgLibDoc/nana/IMAGE_NANA.html\#watson }
$$

IMB Jena Image Library of Biological Macromolecules_additional data on nucleic acid structure

$$
\text { http://www.imb-jena.de/IMAGE.html }
$$

Overview of DNA and RNA structure

$$
\text { http://info.bio.cmu.edu/Courses/BiochemMols/DNA/DNA.html }
$$

Protein Data Bank-includes RNA structures

$$
\text { http://www.rcsb.org/pdb }
$$

\section{Nomenclature}

IUPAC-IUB Commission on Biochemical Nomenclature (CBN) Abbreviations and Symbols for Nucleic Acids, Polynucleotides, and their Constituents-Recommendations 1970

http://www.chem.qmw.ac.uk/iupac/misc/naabb.html

IUPAC-IUB Joint Commission on Biochemical Nomenclature (JCBN) Abbreviations and Symbols for the Description of Conformations of Polynucleotide Chains-Recommendations 1982 (Also reproduced in this volume; see APPENDIX 1C)

http://www.chem.qmw.ac.uk/iupac/misc/pnucl.html

\section{RNA resources}

RNA modification database

http://medstat.med.utah.edu/RNAmods

Compilation of tRNA sequences and tRNA genes

http://www.uni-bayreuth.de/departments/biochemie/trna

Current Protocols in Nucleic Acid Chemistry (2000) A.4A.1-A.4A.3

Copyright $\odot 2000$ by John Wiley \& Sons, Inc. 
The RNA World-large compilation of RNA resources from the Institute of Molecular Biology at Jena. Includes links to databases and web tools for 3-D structure and sequences, as well as links for RNA viruses and a variety of RNA-related software, books, tutorials, and meetings.

http://www.imb-jena.de/RNA.html

The RiboWeb Project-three-dimensional models of the E. coli 30 S ribosomal subunit and 16S rRNA

http://www-smi.stanford.edu/projects/helix/ribo3dmodels/index.html

Ribosomal Database Project

http://www.cme.msu.edu/RDP/html/index.html

RNA Secondary Structures-group I introns and 16S and 23S rRNA

http://pundit.colorado.edu: 8080

RNase P Database

http://jwbrown.mbio.ncsu.edu/RNaseP/home.html

Small RNA Database

http://mbcr.bcm.tmc.edu/smallRNA/smallrna.html

The RNA Society Homepage

http://www.pitt.edu/ rnal/

Nucleic acid informatics

RNA Modeling

http://uracil.cmc.uab.edu/RNA-Modeling/

MFOLD WWW server-fold your own sequences on M. Zuker's server, includes resources such as free energy and enthalpy tables for RNA folding

http://www.ibc.wustl.edu/_zuker/rna/form1.cgi

RNA thermodynamics software and links

http://www.ibc.wustl.edu/ zuker/rna/node3.html

RNADRAW - freeware program for RNA secondary structure calculation and analysis for Microsoft Windows

http://mango.mef.ki.se/ ole/rnadraw/rnadraw.html

MacMolecule (MacOS) and PCMolecule (Windows) for viewing pdb files

http://www.molvent.com

\section{Miscellaneous}

Nucleic Acids Research

http://www3.oup.co.uk/nar/

Translational Active Regions Database (TARD)

http://benpc.bionet.nsc.ru/SRCG/Translation/index.html

Useful Nucleic Acid Chemistry

Web Sites
Extinction coefficient calculation for DNA and RNA oligomers http://paris.chem.yale.edu/extinct.html 
Glen Research-extensive collection of material for the synthesis of modified oligonucleotides

http://www.glenres.com/

Oligonucleotide Calculator- $T_{\mathrm{m}}$, MW, and OD

http://www.embl-heidelberg.de/ toldo/JaMBW/3/1/9/

$T_{\mathrm{m}}$ Determination - allows input of salt and oligonucleotide concentration

http://alces.med.umn.edu/rawtm.html 